\title{
Physical risk associated with vibration at cycling
}

\author{
Marcela Munera, Xavier Chiementin ${ }^{a}$, Samuel Crequy and William Bertucci \\ GRESPI, Groupe de Recherche en Sciences Pour l'Ingénieur, Université de Reims Champagne-Ardenne, \\ 51687 Reims Cedex 2, France
}

Received 7 January 2014, Accepted 15 May 2014

\begin{abstract}
The vibrations undergone by men are a well-known and widely studied risk factor in the industrial world. They are transmitted to the whole body or the upper limbs and they are measured, and limited, according to international standards. Disorders resulting from exposure to vibration are varied in nature: osteoarticular, muscular, vascular, and neurological. In this context, an European Directive 2002/44/EC to the protection of workers exposed to vibration, precises thresholds for vibration exposures and defines the procedure for risk prevention. Nevertheless, the effect of vibration is little studied in sports despite the ubiquity of these. Vibration can induce discomfort, degrading performance or causing musculoskeletal disorders. This paper makes an overview of the studies involving the vibrations during cycling. At first, this paper will summarize the different standards and guidelines relating vibration in humans, which present a guide for the measurement and evaluation of the vibration and exposure limits. Secondly, this paper presents a state of the art vibration effects: (i) the physiological and pathological disorders in athletes, (ii) and the performance. A third part will be devoted to the synthesis of numerical studies that represent the biodynamic response and help to predict the effects of human body vibration. Finally, new research and innovations will be discussed based on studies in other sports.
\end{abstract}

Key words: Vibration risk / sport / standards

\section{Introduction}

Vibration is an oscillatory movement around a stable equilibrium position or a mean trajectory. This kind of movement is omnipresent, for both mechanical systems and men [1]. These vibrations are found in the daily activities, at work and sport. There are two kinds of vibration which are faced by the human body in everyday life: the whole-body vibration and local vibration. According to Griffin [1], "Whole-body vibration occurs when the body is supported on a surface which is vibrating. Local vibration occurs when one or more limbs (or the head) are in contact with a vibrating surface". The resonance is present when the movement in a body is amplified with respect to the input motion. The frequency when this ratio is maximal is called resonance frequency [2]. Along to these resonance phenomena determined for the different parts of the human body [3], excitatory vibrations may be beneficial or harmful. The effects depend on the vibration characteristics: magnitude, frequency, duration and direction [1].

\footnotetext{
${ }^{a}$ Corresponding author:

xavier.chiementin@univ-reims.fr
}

This review covers the vibrations in the human body, especially at cycling. In the first part, the various standards and guidelines relating vibration in humans will be presented. Then, this paper will summarize the most important studies made in relation to vibration in the human body and that have an influence on the understanding of the effects of vibration in cycling. These studies allow to identify the most influential parameters and to know the health and performance factors particularly in cycling. A third part is devoted to the synthesis of numerical studies that represent the biodynamic response and help to predict the reactions of the human body with vibrations. Finally, new research and innovations will be discussed.

\section{Standards and guidelines}

Due to the possible consequences and pathologies derived from exposure to vibration from the industrial activities, certain standards and guidelines have been developed in order to define exposure limits, preventive actions and responsibilities of the employer and employed.

In this section three standards and a European directive that can be applied to cycling are presented. 


\subsection{Standards ISO 5349-1: measurement and evaluation of human exposure to hand-transmitted vibration and ISO 2631-1 mechanical vibration and shock-evaluation of human exposure to whole-body vibration}

Those standards provide a guideline for measurement and evaluation in cases of exposure to vibration transmitted to the hand-arm system [4], whole-body vibration and the vibration with occasional high peak values [5]. The vibrations must be measured and recorded for the three directions of an orthogonal coordinate system. This system has its origin at the point where the vibration enters the human body. This point indicates the vibrations at the interface between the human body and the source of the vibrations. These standards define a frequency weighting and band limiting filters to allow consistent comparison of measurements. The frequency weighting is used to represent the probability of damage in the human body due to different frequencies of exposure.

To assess the vibration it must be necessary to take into account the next parameters: mean vibration in time and in frequency bands, also the time of exposure $(T)$, the intensity, the frequency and the axes of vibration. Under this standard, the vibration assessment should include measurement of the root means square value of weighted acceleration defined by the following equation (Eq. (1))

$$
a_{w}=\left[\frac{1}{T} \int_{0}^{T} a_{w}^{2}(t) \mathrm{d} t\right]^{\frac{1}{2}}
$$

where $a_{w}(t)$ is the weighted acceleration based on time, using frequency weighting factors $W_{i}$, and calculated with the Equation (2). These factors are shown in this standard and they have different values depending on the position of the subject and the activity where the vibration is evaluated (e.g. health, perception, comfort, motion sickness).

$$
a_{w}=\left[\sum_{i}\left(w_{i} a_{i}\right)^{2}\right]^{\frac{1}{2}}
$$

when the acceleration is measured in the three directions at the same point, the total value of the vibrations $a_{h v}$ is computed from the vibrations by an orthonormal coordinate system $\left(a_{w x}, a_{w y}, a_{w z}\right)$ using factors that represent the entry point of vibration, the influence of the position of the subject in each axe $\left(k_{x}, k_{y}, k_{z}\right)$ (Eq. (3)).

$$
a_{h v}=\left(k_{x}^{2} a_{w x}^{2}+k_{y}^{2} a_{w y}^{2}+k_{z}^{2} a_{w z}^{2}\right)^{\frac{1}{2}}
$$

In the hand arm system, although exposure to vibration is measured in terms of acceleration in the contact area, the biological effects and the vibration amplitudes measured may depend in the coupling of the hand and the vibration source. So, it should quantify and record the forces between the hand and the grip area and also the description of the position of the operator.

The vibration exposure depends on the vibration amplitude (represented by total vibration value $a_{h v}$ ) and the duration of exposure. To take into account the duration of exposure, the daily exposure time is used. That is the total time of exposure to vibration during the workday. Daily exposure to vibration is obtained from the amplitude of vibration $\left(a_{h v}\right)$ and duration of daily exposure $(T)$. Daily exposure to vibration is expressed in terms of total value-weighted equivalent continuous vibration frequency for a period of reference $T_{0}$ of $8 \mathrm{~h}$, rated A (8), and calculated using the Equation (4).

$$
A(8)=a_{h v} \times \sqrt{\frac{T}{T_{o}}},
$$

If the total daily exposure to vibrations consists of several operations with different vibration amplitudes, A (8), is obtained with the Equation (5).

$$
A(8)=\sqrt{\frac{1}{T_{0}} \times \sum_{i=1}^{n} a_{h v i}^{2} T_{i}}
$$

where $a_{h v i}$ is the total value for the $i$ th vibrational operation, $n$ is the number of partial vibration exposures and $T_{i}$ is the duration of the $i$ th operation. Each of these values must be set.

\subsection{Directive 2002/44/EC of the european parliament and of the council: minimum safety and health requirements regarding the exposure of workers to risks arising from physical agents}

This Directive set the minimum requirements against risks to health and safety arising from exposure to mechanical vibration. These requirements apply to activities in which workers are exposed during their work to risks from mechanical vibration [6]. It defines the values limit of exposure and the limit triggering an action.

For vibrations transmitted to the hand-arm system: the daily exposure limit value standardized to a reference period of eight hours is $5 \mathrm{~m} . \mathrm{s}^{-2}$ and the daily exposure value normalized to a reference period of eight hours triggering action is set at $2.5 \mathrm{~m} . \mathrm{s}^{-2}$. For vibrations transmitted to the whole body the daily exposure limit value standardized to a reference period of eight hours is $1.15 \mathrm{~m} . \mathrm{s}^{-2}$ and the daily exposure value normalized to a reference period of eight hours triggering action is set at $0.5 \mathrm{~m} . \mathrm{s}^{-2}$.

This directive also defines the obligations of employers for the identification and assessment of risks. These obligations evaluate and, if necessary, measure the levels of mechanical vibrations to which workers are exposed.

During the exposure assessment and prevention of risks the employer must give particular attention to the level, type and duration of exposure, to particular working conditions and any impact on the health and safety of workers. Once the exposure is measured, the employer must take the actions useful to minimize the risks resulting from exposure to mechanical vibration. 

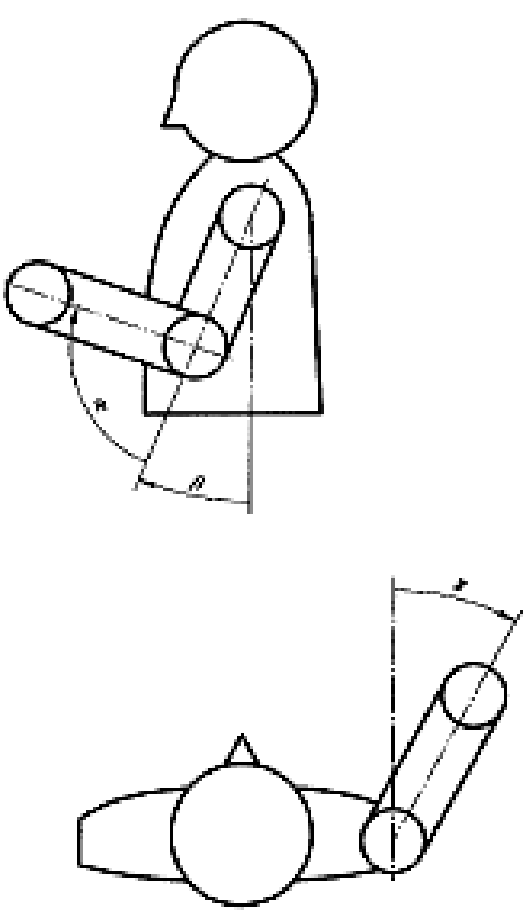

$15^{\circ}<\alpha<120^{*} ;-15^{*}<\beta<\pi 5^{*} ;-15^{*}<\gamma<15^{\circ}, \alpha+\beta<120^{*}$

Fig. 1. Ranges of qualified positions for the arm.

\subsection{Standard ISO 10068: mechanical vibration and shock - Free, mechanical impedance of the human hand-arm system at the driving point}

This standard gives the values of the mechanical response of the hand arm system to vibration and the mechanical equivalent models that represent these values [7]. This response depends on: the direction of vibration, the geometry of the object, the grip forces, posture, muscle tone and anthropometric characteristics. The term "free mechanical impedance to the entry point" is used to describe the dynamic response of the hand-arm to a forced movement of the hand as a function of frequency. The values of the free impedance, expressed as modulus and phase, are provided for the three orthogonal directions (three axes) in the basicentric coordinate system for the hand (Fig. 1).

The reference values of the mechanical impedance are given as a function of frequency for the specified forces. The free impedance values data in this standard are applicable to the following conditions: arm position defined by the Figure 1, rest wrist, the hand grasps a handle having a diameter between $19 \mathrm{~mm}$ and $45 \mathrm{~mm}$ and grip strength between $25 \mathrm{~N}$ and $50 \mathrm{~N}$. The mechanical power transmitted to the hand when they submit a vibrating machine can be calculated by knowing the internal impedance of the source, its movement and the free mechanical impedance. The models presented in this standard (Fig. 2) have 2, 4, and 5 degrees of freedom, which allow the study of two biodynamic functions: mechanical impedance and apparent mass. The selection of the biodynamic function for

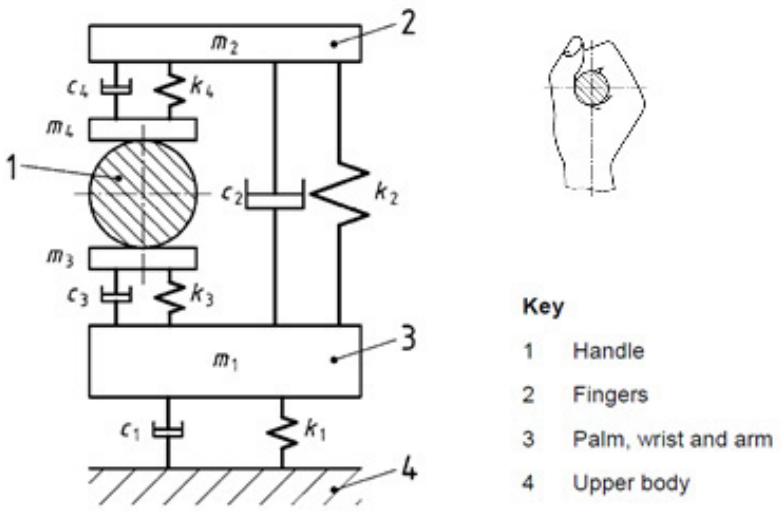

Fig. 2. A 4 DOF mechanical equivalent model of the handarm system.

the model development depends on the application. Apparent mass is used for dynamic force, and impedance is used for power absorption. These models use the same general configuration for each of the three directions.

\subsection{Standard limitations}

The principal limitation of this standard is associated to the measurement of the acceleration for the evaluation of the risk taken in the interface between the source of the vibrations and the human body. That means that this evaluation does not take into consideration the position of the human body or the extremity connected to the vibration source. In sports for example, the alteration of the positions has a strong influence in the performance and the vibrations absorption. It is for this reason that those standards are incomplete for the assessment of the risks on sports or on any activity where movement is present.

\section{Vibration effects}

\subsection{Physiological and pathological disorders}

The first studies about the physiological and pathological effects in the cyclist go back to 1989. Samuelson et al. [8] have searched how the vibrations could affect the physical ability of the cyclist. In this study they used an ergometer placed over a vibrating platform. The eight subjects of this study had realized four tests each one: 2 without vibration and 2 with vibration at a frequency of $20 \mathrm{~Hz}$ in four different days. The experimental test consisted of pedaling at a constant acceleration of $20 \mathrm{~m} . \mathrm{s}^{-1}$ until exhaustion. Heart rate was measured every $10 \mathrm{~min}$ and at the end of the test and the systolic pressure was measured 20 min after the end of the exercise. On heart rate and systolic blood pressure, the results showed no significant differences between the tests with and without vibration. However, the average time of tests with vibration was 47 min against $60 \mathrm{~min}$ for tests without vibration. 6 of 
the 8 subjects showed that the cause of the inability to continue with vibration was an important leg fatigue. The authors concluded that muscle endurance work decreased due to the presence of vibration. In 2007, Suhr et al. [9] worked on the effect of vibrations and hypoxia on the regulation of angiogenesis in the rider. The study involved 12 subjects who performed four training sessions on ergometer in 4 different conditions. The results showed that the endostatin increased in the four conditions of the exercise while the vascular endothelial growth factor (VEGF) increased significantly only in the conditions with vibration. The authors therefore concluded that the vibrations were promoting angiogenesis.

In 2009 Sperlich et al. [10] completed the study of Samuelson et al. [8] focusing their research on the effect of vibrations on the cardiopulmonary system of the cyclist. Their study involved 12 cyclists; each one realized a test on ergometer with vibration and another without vibration (the ergometer is placed on a vibration platform with a frequency of $20 \mathrm{~Hz}$ and amplitude of $4 \mathrm{~mm}$ ). The exercise was to increase the pedaling power of $50 \mathrm{~W}$ every 5 min starting with an effort to $100 \mathrm{~W}$. The following data were measured during and after the exercise: heart rate, blood lactate concentration, perception of muscular effort and oxygen consumption. As in the study of Samuelson et al. [8] no significant difference in heart rate was revealed. The comparison of lactate rate and perception of muscular effort did not show significant differences either. Contrariwise, at pedaling power of $250-300 \mathrm{~W}$, the oxygen consumption was significantly higher in the exercise with vibration. This greater respiratory demand can be explained by a greater demand for oxygen by the muscles of the extremities due to micro contractions caused by vibration.

Several articles in the literature refer to or analyze pathologies occurring during cycling without direct trauma. They are described briefly: Rtaimate et al. [11] reported a clinical case of aneurysm of the ulnar artery. This pathology is present in sports where the hand is under repeated traumatic impacts. Haloua et al. [12] studied the ulnar nerve in amateur cyclists. The main reason for the occurrence of this disease appears to be the lack of training, poor road position and inadequate equipment. The IFCM (French Institute for Hand Surgery) refers to the compartment syndrome in the upper limb as pathology found in cyclist and caused by prolonged strength on the handlebar grip without a recovery period. Saraux et al. [13] list the pathologies found depending on the sport. For the pathologies on the upper extremity for the cyclists, they found mainly: phlebitis and arterial compression, compartment syndrome of the forearm, flexor carpi radialis tendinitis, epicondylitis, Quervain tenosynovitis, radial and ulnar stylö̈ditis and carpal tunnel.

\subsection{Performance}

In cycling, the vibration is intrinsic to the activity. This vibration is mainly caused by the surface when this is uneven. It has been reported several studies which investigate the influence of different types of road surface in the comfort of the cyclist [14]. They show that asphalt presents the lower acceleration effective value and cobblestone presents the higher. Giubilato et al. [15] developed a method to measure and compare the vibrational response of different wheels, under different roughness of road surface and to different speeds. They found that different wheel models equipped with the same tyre inflated at the same air pressure level can show different vibrational response to road roughness excitations and that higher speed determines a higher vibration amplitude.

In the study by Arpinar-Avsar [16], a field and laboratory study of vibrations is presented. In this study they use the protocol established by the standard ISO2631, concerning the placement of the sensors and the analysis of the acceleration measured. They used tri-axial accelerometers and an EMG system for the data acquisition. They analyze the frequency and amplitude characteristics of vibration exposed to the bicycle and the rider under different characteristics.

The study conducted by Peretti et al. [17] shows the difference of that comfort for two different kinds of bikes indicating a slightly lower acceleration in a racing bike than in a city bike. Other studies focus on the resistance of the rider at different vibrations conditions [8,14] and also the level of vibration under different conditions as speed [18] or tyre air pressure in the bike [17,19]. Particularly, in the study presented by Chiementin et al. [18] the evaluation of vibrations is assessed by using the standard ISO5349 and measuring the vibrations in the handle as well as the transmission through the arm.

\section{Numerical studies}

A numerical study is based in a model of the mechanical behavior of the system. These models can be used to explain a system and the influence of different parameters in its behavior. There are several kinds of models used for the study of vibrations on the human body. The mathematical models who represent the relation between the inputs and the outputs with equations, can be used to optimize the design of tools like seating systems [20] or suspension systems for bikes [21]. The mechanical equivalent models represent a physical process with elements like masses, springs, dampers, beams and others; using this kind of model is possible to represent the biodynamic response to vibrations in terms of mechanical impedance [22], apparent mass [23] or relative to the frequency [24], and is also possible to study the vibration transmission [25] and different ways to reduce it [26]. Particularly in cycling, He et al. [27] show a model of the response to vibration due to uneven surface of the road. The finite element model (FEM) is a numerical technique for finding approximate solutions of partial differential equations (PDE) and their systems. This kind of model is usually used to represent the hand-arm system, the local response to vibrations on a finger [28], the modal analysis of long bones [29] or of all the body [30]. 
Finally, the multi-body models are composed by discrete segments connected by inertial kinematics joints that can incorporate force elements; this kind of model allows to study the vibration response in the human body [31], at cars [32] or in a work environment [33] and the modal analysis of the human body [34].

\section{Perspectives}

Several studies show the influence of vibration in the performance of physical activities and sports. This influence can be shown in two different situations: when the vibration is caused by the activity itself and when the vibration is applied to the activity for study the different changes in the performance, strength and flexibility. In the first case we found cycling as well as other sports like ski, golf and tennis [35-37]. In the second case the vibration can be whole body vibration or just applied to the hand- arm system. For the whole body vibration there are studies that show the decrease of transmissibility to the head when the frequency increases [38] the effects in the increase of the force [39] the vertical jump performance $[24,39,40]$, the movement range [40] and flexibility [41]; for the hand-arm system the studies show a decrease of elbow torque [42], a reduction of the ability to apply a precise quantity of force [43] and a diminution of the force-recall performance [44] under vibration. The results of this second case can be extended to the study in cycling because it affects the extremities in a similar way. These studies propose protocols that can be applied in cycling in laboratory and field analysis.

It is rarely mentioned the cyclist vibration exposure in a bike over the road. Yet it seems that as for occupational diseases, the vibrations of the bike could be promoting the arrival of the aforementioned pathologies. The study by Boileau et al. [45] states that the effect of vibration depends on the intensity and distribution in the frequency domain. They explain that there are standardized test codes (ISO 8662 series of standards) describing the methods used in the laboratory to determine the vibration emission values of tools belonging to the same category. This method allows a selection of tools less vibrating. Future work would be addressed to draw an analogy with the rider and create an experimental protocol to test the vibration in the interface human-bicycle. Also it will be set off to determine the potential effect of vibrations on the performance of the cyclist and the possible occurrence of diseases. Exposure to vibrations experienced by the cyclist can then be compared with the exposure value given by the guideline. It is important to remember that the most harmful vibration for a joint will be the one whose amplitude and especially the frequency is closest to the resonance frequency of this joint.

\section{References}

[1] M.J. Griffin, Handbook of human vibration, Academic press, 1990
[2] J. Sandover, Vibration and People, Clinical Biomechanics (1986)

[3] S. Kitazaki, M.J. Griffin, Resonance behaviour of the seated human body and effects of posture, J. Biomech. 31 (1998) 143-149

[4] ISO 5349-1, Mesurage et évaluation de l'exposition des individus aux vibrations transmises par la main, Afnor, 2002

[5] ISO 2631-1, Vibrations et chocs mécaniques-Evaluation de l'exposition des individus à des vibrations globales du corps, Afnor, 1997

[6] Directive2002/44/CE, Directive2002/44/CE du parlement européen et du conseil concernant les prescriptions minimales de sécurité et de santé relatives à l'exposition des travailleurs aux risques dus aux agents physiques, Journal Officiel des Communautés Européennes (10) (2002) 13-19

[7] ISO10068, Mechanical vibration and shock - Mechanical impedance of the human hand-arm system at the driving point, Afnor, 2012

[8] B. Samuelson, L. Jorfeldt, B. Ahlborg, Influence of vibration on work performance during ergometer cycling, Ups. J. Medical Sci. 94 (1989) 73-79

[9] F. Suhr, K. Brixius, M. de Marees, B. Bolck, H. Kleineder, S. Achtzehn, W. Bloch, J. Mester, Effects of short-term vibration and hypoxia during high-intensity cycling exercise on circulating levels of angiogenic regulators in humans, J. Appl. Physiol. 103 (2007) 474-483

[10] B. Sperlich, H. Kleinoeder, Physiological And Perceptual Responses Of Adding Vibration To Cycling, J. Exercise Physiol. 12 (2009) 40-46

[11] M. Rtaimate, E. Farez, J. Lariviére, M. Limousin, P. Laffargue, Anuerysm of the ulnar artery in a mountain biker, A case report and review of the literature, Case Reports, Clinique Lille-Sud, 2002

[12] J.P. Haloua, J.P. Collin, L. Coudeyre, Paralysis of the ulnar nerve in cyclists, Annales de Chirurgie de la Main 6 (1987) 282-287

[13] A. Saraux, P. Kervarrec, V. Devauchelle-Pensec, S. Jousse-Joulin, C. Destombe, Y. Guillodo, Principales pathologies rhumatologiques observées selon les sports, Revue du Rhumatisme 74 (2007) 547-552

[14] C. Hölzel, F. Höchtl, V. Senner, Cycling comfort on different road surfaces, Procedia Eng. 34 (2012) 479-484

[15] F. Giubilato, N. Petrone, A method for evaluating the vibrational response of racing bicycles wheels under road roughness excitation, Procedia Eng. 34 (2012) 409-414

[16] P. Arpinar-Avsar, Vibration transmission to bicycle and rider: a field and a laboratory study, Middle East Technical University, 2009

[17] A. Peretti, L. Pignalosa, F. Bonomini, A. Paoli, G. Bartolucci, Vibrazioni su biciclette da corsa e da città, Giornale degli Ignienisti Industriali 34 (2009) 283-293

[18] X. Chiementin, M. Rigaut, S. Crequy, W. Bertucci, Handarm vibration in cycling, J. Vib. Control (2011)

[19] M. Olieman, R. Marin-Perianu, M. Marin-Perianu, Measurement of dynamic comfort in cycling using wireless acceleration sensors, Procedia Eng. 34 (2012) 568573 
[20] S.D. Smith, Modeling differences in the vibration response characteristics of the human body, J. Biomech. 33 (2000) 1513-1516

[21] E.L. Wang, M. Hull, A Dynamic System Model of an Off-Road Cyclist, J. Biomech. Eng. 119 (1997) 248-253

[22] R.G. Dong, J.H. Dong, J.Z. Wu, S. Rakheja, Modeling of biodynamic responses distributed at the fingers and the palm of the human hand-arm system, J. Biomech. 40 (2007) 2335-2340

[23] S. Rützel, B. Hinz, H.P. Wölfel, Modal description-A better way of characterizing human vibration behavior, J. Sound Vib. 298 (2006) 810-823

[24] L. Wood, C. Suggs, C. Abrams, Hand - Arm Vibration Part III, J. Sound Vib. 57 (1978) 157-169

[25] A. Truta, A.F. Pop, M. Bălcău, M. Arghir, Development of a biomechanical model to study the horizontal vibration transmitted from shoulder to head, PAMM 11 (2011) $129-130$

[26] T. Cherian, S. Rakheja, R.B. Bhat, An analytical investigation of an energy flow divider to attenuate handtransmitted vibration, Int. J. Indust. Ergon. 17 (1996) $455-467$

[27] Q. He, X. Fan, D. Ma, Full Bicycle Dynamic Model for Interactive Bicycle Simulator, J. Comput. Inform. Sci. Eng. 5 (2005) 373

[28] R.G. Dong, J.Z. Wu, D.E. Welcome, Recent advances in biodynamics of human hand-arm system, Industrial Health 43 (2005) 449-471

[29] B. Couteau, M.C. Hobatho, R. Darmana, J.C. Brignola, J.Y. Arlaud, Finite element modelling of the vibrational behaviour of the human femur using CT-based individualized geometrical and material properties, J. Biomech. 31 (1998) 383-386

[30] S. Kitazaki, M.J. Griffin, A modal analysis of whole-body vertical vibration, using a finite element model of the human body, J. Sound Vib. 200 (1997) 83-103

[31] F. Li, Constrained Multi-body Dynamics Method to Study Musculoskeletal Disorders Due To Human Vibration, University Of Cincinnati, 2007

[32] Z. Liu, E. Zhang, Z. Ji, Simulation and Experimental Study of Human Riding Comfort in Dynamic ManAutomobile System, 2008, pp. 577-587

[33] A. Madakashira-Pranesh, Experimental and analytical study of transmission of whole body vibration to segments of the seated human body, Concordia University, 2011
[34] T. Yoshimura, K. Nakai, G. Tamaoki, Multi-body dynamics modelling of seated human body under exposure to whole-body vibration, Industrial health 43 (2005) 441447

[35] C.L. Stroede, L. Noble, H.S. Walker, The effect of tennis racket string vibration dampers on racket handle vibrations and discomfort following impacts, J. Sports Sci. (1999)

[36] L. Manin, M. Poggi, N. Harvard, Vibrations of table tennis racket composite wood blades: modeling and experiments, Procedia Eng. 34 (2012) 694-699

[37] J.R. Roberts, R. Jones, N.J. Mansfield, S.J. Rothberg, Evaluation of vibrotactile sensations in the "feel" of a golf shot, J. Sound Vib. 285 (2005) 303-319

[38] J. Mester, P. Spitzenfeil, J. Schwarzer, F.Seinfriz, Biological reaction to vibration-implications for sport, Journal of Science and Medicine in Sport /Sports Medicine Australia 2 (1999) 211-226

[39] M. Cardinale, J. Wakeling, Whole body vibration exercise: are vibrations good for you, British Journal of Sports Medicine 39 (2005) 585-589

[40] J. Cronin, M. Nash, C. Whatman, The acute effects of hamstring stretching and vibration on dynamic knee joint range of motion and jump performance, Physical therapy in sport: official journal of the Association of Chartered Physiotherapists in Sports Medicine 9 (2008) 89-96

[41] V. Gerodimos, A. Zafeiridis, K. Karatrantou, T. Vasilopoulou, K. Chanou, E. Pispirikou, The acute effects of different whole-body vibration amplitudes and frequencies on flexibility and vertical jumping performance, Journal of science and medicine in sport / Sports Medicine Australia 13 (2010) 438-43

[42] B. Friesenbichler, A. Coza, B.M. Nigg, Reduced elbow extension torque during vibrations, J. Biomech. 45 (2012) 2203-2207

[43] S.T. Osis, D.J. Stefanyshyn, Vibration at the wrist and elbow joints during the golf swing reveals shaft-specific swing kinematics, Procedia Eng. 2 (2010) 2637-2642

[44] T.W. McDowell, S.F. Wiker, R.G. Dong, D.E. Welcome, Effects of vibration on grip and push force-recall performance, Int. J. Indust. Ergon. 37 (2007) 257-266

[45] P.E. Boileau, H. Scory, J. Boutin, Exposition aux vibrations mécaniques engendrées par les meuleuses portatives, IRSST, 1988 